\title{
PENYULUHAN BELA LINGKUNGAN LAUT PADA NELAYAN PANGGONG DI MEULABOH
}

\section{DEFINATION OF MARTIAL ENVIRONMENT ON THE FISHERMAN OF PANGGONG IN MEULABOH}

\author{
Jun Musnadi Is ${ }^{1}$, Rinawati ${ }^{1}$, Zulfadhli², Chairiyaton ${ }^{3}$ \\ ${ }^{1}$ Program Studi Ilmu Kesehatan Masyarakat, Fakultas Kesehatan Masyarakat Universitas Teuku Umar \\ ${ }^{2}$ Program Studi Akuakultur, Fakultas Perikanan dan IImu Kelautan Universitas Teuku Umar \\ ${ }^{3}$ Program Studi Ekonomi Pembangunan, Fakultas Ekonomi Universitas Teuku Umar \\ Korespondensi: junmusnadi@utu.ac.id
}

\begin{abstract}
ABSTRAK
Gampong Panggong terletak dipesisir kota meulaboh yang banyak penduduknya bermata pencaharian sebagai nelayan yang sering membawa bekal makanan instan ketika melaut dan membuang wadah kemasan plastik dan kaleng kedalam laut sebagai sampah dimana tempat mereka mencari ikan. Tujuan kegiatan ini adalah mengadakan penyuluhan untuk meningkatkan pengetahuan dan kesadaran para nelayan agar membuang sampah pada tempatnya. Kegiatan pengabdian dilakukan dimulai dengan tahap persiapan, sosialisasi, penyuluhan dan diskusi tentang pengelolaan sampah. Hasil kegiatan pengabdian ini adalah peningkatan pemahaman dari level $71,05 \%$ sebelum dilakukan pelatihan menjadi $96,71 \%$ setelah pelaksanaan program dan kesadaran masyarakat nelayan mengenai buang sampah.
\end{abstract}

Kata kunci: laut, nelayan, sampah

\begin{abstract}
Panggong Village is located on the coast of the city of Meulaboh where many residents earn a living as fishermen who often bring instant food supplies when they go out to sea and throw plastic containers and cans into the sea as rubbish where they find fish. The purpose of this activity is to provide counseling to increase the knowledge and awareness of the fishermen so that they throw garbage in its place. Community service activities begin with the preparation, outreach, outreach and discussion about waste management. The result of this community service activity was an increase in understanding from the level of 71.05 percent before the training was held to 96.71 percent after the implementation of the program and the awareness of the fishing community regarding waste disposal.
\end{abstract}

Keywords: sea, fishermen, garbage

\section{PENDAHULUAN}

Panggong merupakan salah satu desa atau gampong yang terletak pada kecamatan johan pahlawan yang berada dikawasan pesisir kota meulaboh ibu kota kabupaten aceh barat privinsi aceh yang juga merupakan kawasan yang terkena dampak tsunami beberapa tahun yang lalu.

Jumlah penduduk Gampong Panggong sebanyak 1.377 jiwa yang terdiri dari 364 KK. Sebanyak 162 (44.5\%) KK bekerja sebagai Nelayan. Untuk memenuhi kebutuhan sehari-hari sebahagian penduduk mencari nafkah dilaut mencari ikan, udang dan lainlain yang menggunakan alat tangkap tradisional seperti jaring, jala dan pancing dengan menggunakan media transportasi perahu dan bot. Hal ini terjadi karena gampong panggong tersebut berada dilokasi yang dekat dengan bibir pantai Samudera Hindia. 


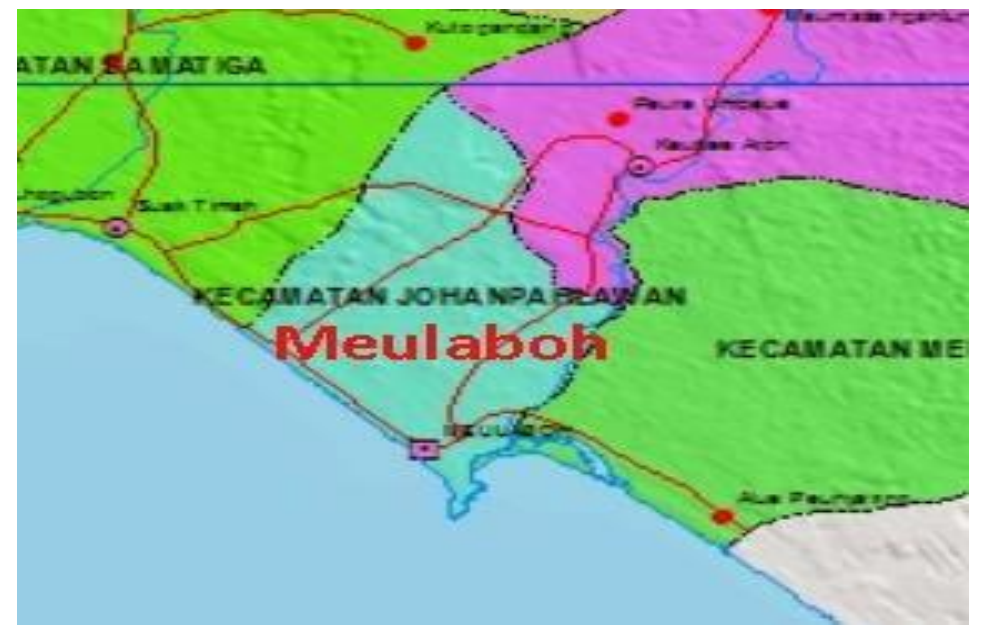

\section{Gambar 1. Peta Kecamatan Johan Pahlawan Kabupaten Aceh Barat}

Laut adalah sistem perairan samudra berair asin yang didalamnya terdapat berbagai macam biota laut dengan satu ekosistem. Laut juga merupakan tempat mencari nafkah bagi para nelayan untuk memenuhi kebutuhan hidupnya. Nelayan adalah orang-orang yang sehari-harinya bekerja menangkap ikan atau biota lainnya yang hidup di dasar, kolom maupun permukaan perairan laut.

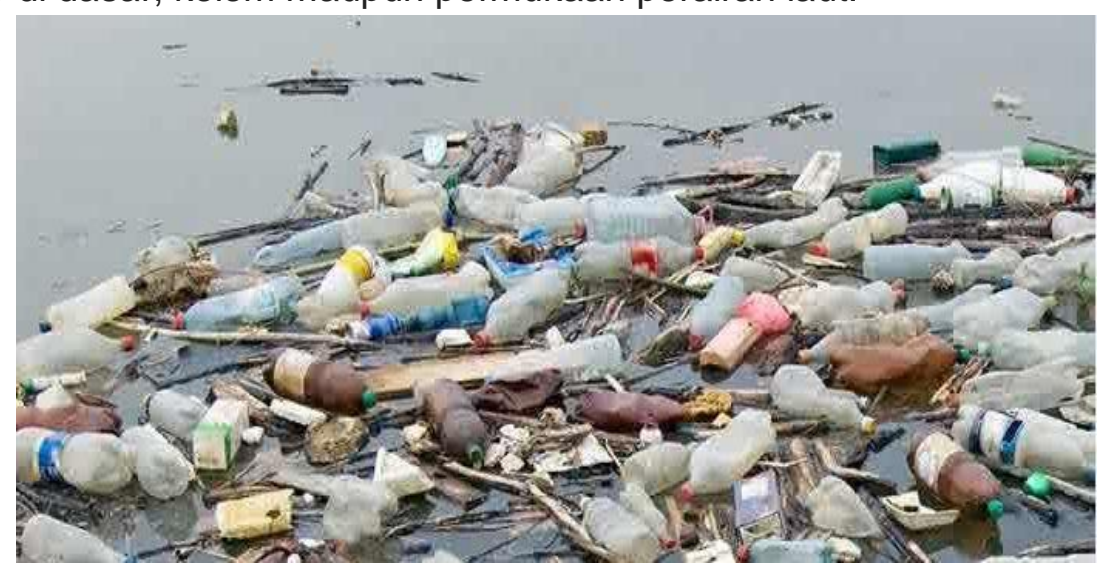

Gambar 2. Sampah yang terdapat diperairan permukaan laut

Sampah adalah material sisa yg dibuang sebagai hasil dari proses produksi, baik itu industri maupun rumah tangga. Komunitas Divers Clean Action (DCA) merilis temuan bahwa 63 persen sampah di lautan Indonesia berupa sampah plastik sekali pakai. Sampah ini sulit didaur ulang karena prosesnya lama dan harga yang rendah di tingkat pengepul. Kesadaran masyarakat tentang bahaya buang sampah anorganik di laut dan teknis pengendalian buang sampah yang baik dan benar untuk dapat menjaga kelestarian laut dan ekosistemnya perlu terus ditingkatkan dan disosialisasikan pada para nelayan.

Para Nelayan merupakan agen penggerak masyarakat yang potensial dijadikan sebagai sasaran program penyuluhan tersebut. Melalui kegiatan ini diharapkan dapat meningkatkan pengetahuan tentang bahaya buang sampah anorganik di laut dan teknis pengendalian buang sampah yang baik dan benar dalam menjaga kelestarian laut dan ekosistemnya. 


\section{METODE}

\section{Kerangka Pemecahan Masalah}

Dalam upaya menumbuhkan kesadaran masyarakat nelayan untuk tidak membuang sampah dilaut tetapi harus pada tempatnya ketika sedang melaut, dilakukan melalui penjelasan materi tentang bahaya buang sampah anorganik di laut dan teknis pengendalian buang sampah yang baik dan benar untuk dapat menjaga kelestarian laut dan ekosistemnya. Untuk mengukur perubahan pengetahuan dan keterampilan maka dilakukan pre-test dan posttest.

\section{Realisasi Pemecahan Masalah}

Penyampaian materi penyuluhan bela lingkungan laut pada nelayan di Gampong Panggong Kecamatan Johan Pahlawan Kabupaten Aceh Barat dilaksanakan di Balai tempat pendaratan ikan. Penyampaian teori dan penyuluhan dilaksanakan dengan metode diskusi tanya jawab. Untuk mengetahui tingkat pengetahuan peserta nelayan tentang bahaya buang sampah anorganik di laut dan teknis pengendalian buang sampah yang baik dan benar maka dilakukan pre-test. Selanjutnya untuk mengetahui efektifitas penyuluhan sehingga dapat meningkatkan pengetahuan peserta maka dilakukan post-test.

\section{Metode Pelaksanaan}

1. Melakukan pemberitahuan tentang kegiatan pengabdian yang akan dilaksanakan di Gampong Panggong.

2. Berkoordinasi dengan Panglima Laot, perangkat gampong serta para nelayan untuk teknik pelaksanaan.

3. Pretest kepada peserta yang akan mengikuti penyuluhan untuk melihat berapa besar tingkat pengetahuan peserta terhadap sampah sebelum diberikan materi dengan menggunakan form kuisioner tentang bahaya buang sampah anorganik di laut dan teknis pengendalian buang sampah yang baik dan benar.

4. Melaksanakan penyuluhan dengan memberi teori-teori yang berkaitan dengan materi tentang sampah

5. Melaksanakan diskusi tanya jawab.

6. Melakukan posttest untuk mengukur efektifitas pelaksanaan penyuluhan.

\section{HASIL DAN PEMBAHASAN}

Program pengabdian kepada masyarakat yang diikuti oleh para nelayan Gampong Panggong Kecamatan Johan Pahlawan Kabupaten Aceh Barat. Pada pelaksanaan program penyuluhan ini diikuti secara antusias oleh peserta penyuluhan. Para Nelayan mendapatkan penjelasan berkaitan tentang bahaya buang sampah anorganik di laut dan teknis pengendalian buang sampah yang baik dan benar. Dalam praktek nya para nelayan lebih ditekankan agar mau mengelola sampah dengan menyediakan tempat sampah dan tidak membuang sampah kedalam laut agar ekosistem laut tidakterganggu.

Pengetahuan yang diperoleh diharapkan dapat diterapkan sehingga diperlukan pengawasan dan pendampingan. Peran dan antusiasme para nelayan ditunjukkan dengan harapan mereka untuk mendapatkan penyuluhan selanjutnya berkaitan dengan pemamfaatan dan daur ulang sampah. 
Hal ini menunjukan bahwa para nelayan merupakan kader potensial untuk memberikan pengaruh perubahan bagi masyarakat pesisir. Sehingga diperlukan upaya komunikasi yang lebih intensif untuk dapat berlangsungnya program-program pendampingan dan pemberdayaan masyarakat.

Indikator keberhasilan kegiatan pengabdian kepada masyarakat berdasarkan pengamatan langsung selama kegiatan berlangsung dan pengisian lembar kuisioner (Tabel ) yang dilanjutkan dengan analsisis.

Tabel 1. Hasil Analsis Kuesioner Pre-Test dan Post-Test

\begin{tabular}{|c|c|c|c|c|c|}
\hline \multirow{3}{*}{ No } & \multirow{3}{*}{ Pengetahuan } & \multicolumn{4}{|c|}{ (\% Jawaban) } \\
\hline & & \multicolumn{2}{|c|}{ Sebelum Pelatihan } & \multicolumn{2}{|c|}{ Setelah Pelatihan } \\
\hline & & Benar & Salah & Benar & Salah \\
\hline 1 & $\begin{array}{l}\text { Tempat pembuangan } \\
\text { sampah }\end{array}$ & 100 & 0 & 100 & 0 \\
\hline 2 & $\begin{array}{l}\text { Bahaya buang } \\
\text { sampah }\end{array}$ & 89,47 & 10,53 & 100 & 0 \\
\hline 3 & $\begin{array}{l}\text { Manfaat sampah dari } \\
\text { laut }\end{array}$ & 79,95 & 21,05 & 100 & 0 \\
\hline 4 & Jenis-jenis sampah & 15,79 & 84,21 & 89,47 & 10,53 \\
\hline 5 & $\begin{array}{l}\text { Dampak sampah } \\
\text { dilaut }\end{array}$ & 36,84 & 63,16 & 89,47 & 10,53 \\
\hline 6 & $\begin{array}{l}\text { Kepemilikan tempat } \\
\text { sampah }\end{array}$ & 89,47 & 10,53 & 100 & 0 \\
\hline 7 & $\begin{array}{l}\text { Pemisahan jenis } \\
\text { sampah }\end{array}$ & 94,74 & 5,26 & 100 & 0 \\
\hline 8 & $\begin{array}{l}\text { Teknik penyimpanan } \\
\text { sampah }\end{array}$ & 63,16 & 36,84 & 94,74 & 5,26 \\
\hline & Rata-rata total & 71,05 & 28,95 & 96,71 & 3,29 \\
\hline
\end{tabular}

Berdasarkan pada hasil analisi pada Tabel menunjukkan bahwa para nelayan Gampong Panggong telah mengenal sampah, akan tetapi belum memiliki pengetahuan yang cukup berkaitan dengan teknik pengelolaan sampah yang baik sesuai dengan syarat kesehatan.

Hal ini terlihat dari hasil pre-test berkaitan dengan pengetahuan pembuangan sampah yaitu jenis-jenis sampah (15,79\%) dan dampak buang sampah dilaut $(36,84 \%)$ serta teknik penyimpanan sampah $(63,15 \%)$. Sebagian besar peserta mengenal dan tau sampah dengan melihat dalam kehidupan sehari-hari, sehingga beranggapan bahwa sampah hanya bisa dibuang begitu saja dialam tanpa mengetahui dampak yang merugikan bagi alam sekitar seperti ekosistem dilaut. Dalam penyuluhan ini diperkenalkan tentang bahaya buang sampah anorganik di laut dan teknis pengendalian buang sampah yang baik dan benar. Sehingga melalui pelatihan ini peserta memahami teknik dasar pengelolaan untuk sampah dan dapat mempraktekan di dalam kehidupan sehari-hari. Setelah penyuluhan pengetahuan tentang jenis-jenis sampah meningkat mencapai $(89,47 \%)$. 

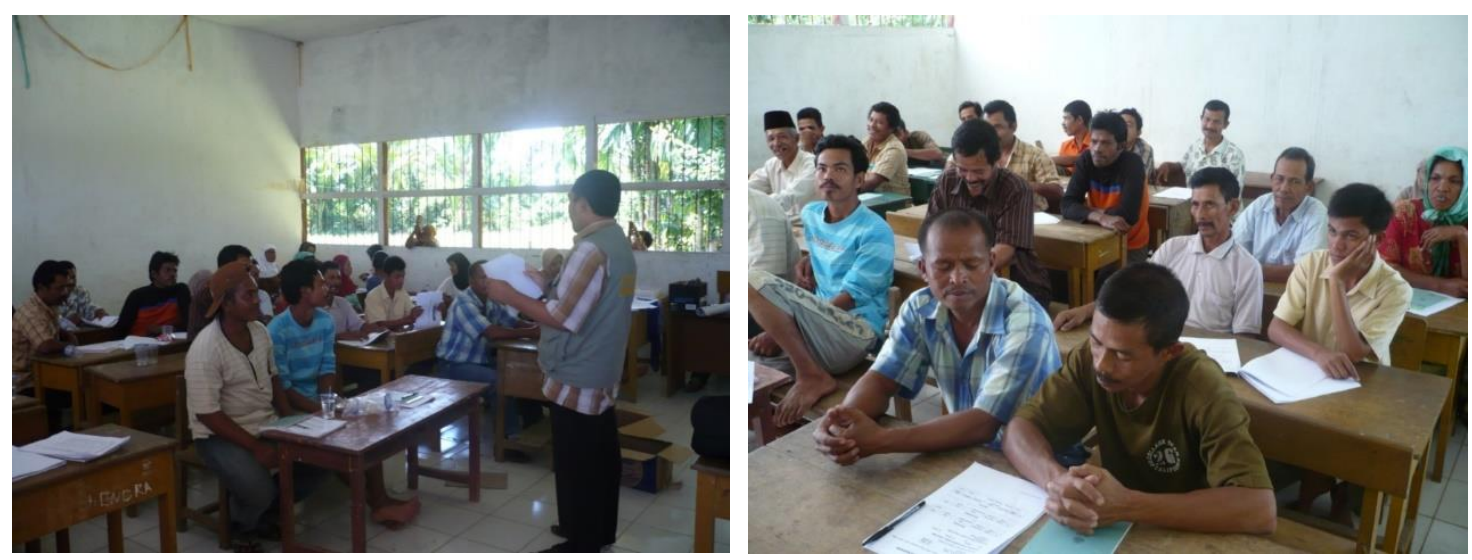

Gambar 3. Dokumentasi kegiatan penyuluhan

Berkaitan dengandampak buang sampah dilaut,peserta pelatihan masih beranggapan bahwa laut yang luas tidak akan berdampak apa-apa dengan ekosistem laut ( jawaban yang salah mencapi 63,16\%). Melalui penyuluhan dijelaskan bahwa dampak buang sampah dilaut dapat merusak ekosistem laut. Setelah dilakukan postest terjadi peningkatan pengetahuan tentang dampak buang sampah dilaut yaitu jawaban benar mencapai 89,47 persen. Demikian pula dengan teknik penyimpanan sampah yang benar pada tempatnya pada saat pretest $63,16 \%$ terjadi peningkatan pemahaman menjadi $94,74 \%$.

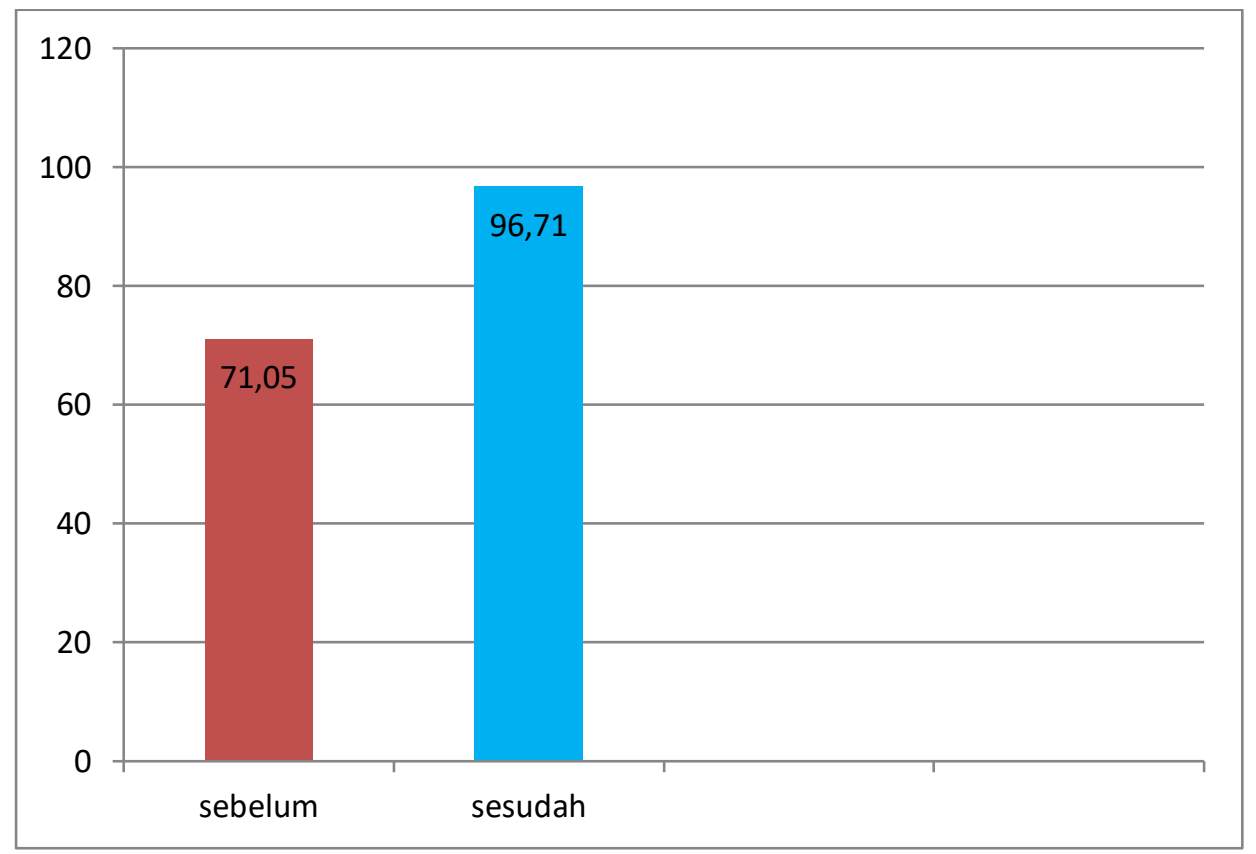

Gambar 4. Grafik peningkatan pengetahuan nelayan sebelum dan sesudah penyuluhan

Secara keseluruhan pada penyuluhan ini dapat memberikan peningkatan pengetahuan dan pemahanan bagi pesertanya yaitu pada saat pretest dengan rata-rata jawaban benar mencapai 71,05 persen, setelah dilakukan penyuluhan terjadi peningkatan jawaban benar mencapai 96,71 persen. 


\section{SIMPULAN}

Penyuluhan yang dilakukan di Gampong Panggong Kecamatan Johan Pahlawan dapat meningkatkan pengetahuan dan pemahaman para Nelayan berkaitan tentang bahaya buang sampah anorganik di laut dan teknis pengendalian buang sampah yang baik dan benar untuk dapat menjaga kelestarian laut dan ekosistemnya.

\section{Ucapan terimakasih}

Program Pengabdian Kepada Masyarakat ini merupakan salah satu dari kegiatan Tri darma Perguruan Tinggi Tahun 2019 yang di lakukan bersama mahasiswa pada masyarakat Nelayan. Ucapan terimakasih kepada Rektor Universitas Teuku Umar Dekan Fakultas Kesehatan Masyarakat dan Dekan Fakultas perikanan dan ilmu kelautan atas dukungannya dan juga pemerintah daerah khususnya panglima laot dan para Nelayan yang ada di seluruh wilayah Kabupaten Aceh Barat.

\section{DAFTAR PUSTAKA}

Aboejoewono, A., 1985 Pengelolaan Sampah Menuju ke Sanitasi Lingkungan dan Permasalahannya, Jakarta: Wilayah DKI Jakarta Sebagai Suatu Kasus,

Bungin, Burhan, 2003, Analisis Data Penelitian Kualitatif Pemahaman Filosofis dan Metologi ke Arah Penguasaan Model Aplikasi, Jakarta: Raja Grafindo Persada

Eko Wahyudi, Achmad, 2013, SKRIPSI, Pemberdayaan Masyarakat Nelayan Oleh Kelompok Nelayan Di Desa Palang Kecamatan Palang Kabupaten Tuban (Surabaya : IAIN Sunan Ampel)

Profil Gampong 2018, Gampong Panggong Kecamatan Johan Pahlawan Kabupaten Aceh Barat

Hamdan, 2005, THESIS, Evaluasi Program Pemberdayaan Ekonomi Masyarakat Pesisir (PEMP 2001) Di Kabupaten Jepara Dalam Upaya Peningkatan Pendapatan Masyarakat Pesisir, Semarang : Universitas Diponegoro

Irianto, Surya, 2008, Nelayan Di Mata Kita Sebuah Perspektif Berpikir Sistem, Pekanbaru: CV. Sukabina

Kusnadi, 2004, Polemik Kemiskinan Nelayan, Bantul : Pondok Edukasi \& Pokja Pembaruan

Sahwan, F.M.,dkk, 2005. Sistem Pengolahan Limbah Plastik di Indonesia. Jurnal Teknologi Lingkungan P3TI_BPPT., 6, 1, 311-31

Surono, Ono, 2015, Koperasi Nelayan Pengelolaan Sumber Daya Perikanan Tangkap Berbasis Ekonomi Gotong Royong, Jakarta : PT. Wahana Semesta Intermedia 